\title{
NOTES ON A CASE OF CONGENITAL HEART DISEASE WITH CYANOTIC EPISODES ${ }^{1,2}$
}

\author{
By W. F. HAMILTON, J. A. WINSLOW, and W. F. HAMILTON, JR. \\ (From the Departments of Physiology, Medicine, and Roentgenology, University of Georgia, \\ School of Medicine, Augusta, Ga.)
}

(Received for publication July 5, 1949)

Recent papers on cyanotic congenital heart disease $(1-8)$ contain references to patients that suddenly become cyanotic, lose consciousness, and suffer dyspnea or other signs of cardio-respiratory distress.

When such episodes are the result of exercise or of other factors which give rise to an increase in oxidations there might be some decrease in arterial saturation, even though the intracardiac shunt remains constant in the relative amount of venous blood which mixes into the arterial stream. If we imagine a case with large intracardiac shunt in which blood in the pulmonary vein is $100 \%$ saturated and two-thirds of the arterial stream is venous blood, and if we were to assume further the resting mixed venous saturation to be $50 \%$, we would have an arterial saturation of $67 \%$. During exercise as violent as such a patient could sustain, it is doubtful that the saturation mixed venous blood could get below $20 \%$. Under these conditions, the arterial saturation would be $47 \%$. Even if the mixed venous blood had no oxygen at all, the saturation of the arterial blood would be $33 \%$. If the shunt were smaller, and only onethird of the aortic stream were venous blood, arterial saturation would vary from $83 \%$ to $73 \%$ as the saturation of the mixed venous blood is reduced from $50 \%$ to $20 \%$, by increased oxidations.

It is obvious that the activity needed to produce the changes in arterial saturation indicated above is considerable, and that some other mechanism is necessary to account for the occasional unheralded episodes of cyanosis which have been described.

It is possible that these episodes have a vasomotor basis but no mechanism that would account for them has been described. Could constriction of the pulmonary blood vessels be responsible for

\footnotetext{
${ }^{1}$ This work was supported by a grant from the Life Insurance Medical Research Fund.

2 Technical assistance by Mrs. Kay Allen is gratefully acknowledged.
}

changes in the size of the pulmonary stream and hence for changes in the size of the shunt? In the tetralogy of Fallot the resistance is made by a strong stenosis of the pulmonary artery and is probably fixed. Similarly, the structural arteriolar changes that are seen in the lungs in the Eisenmenger complex (3) result in a high resistance to pulmonary blood flow which is also probably fixed. Moreover it is extremely doubtful that the pulmonary bed is able, in response to reflex vasomotor activity, to constrict and dilate sufficiently to produce appreciable changes in its peripheral resistance (9). The direct constrictor effect of low oxygen in the inspired air is of course irrelevant (10).

Another possibility is that alterations in the systemic arterial pressure may passively affect the pulmonary blood flow so as to lead to changes in arterial saturation of a larger order than can be explained as resulting from increased oxidations with a constant shunt. In the case to be described here the sudden onset of episodes of cyanosis seems to be related to an instability in the regulation of arterial pressure dating from a recent illness. Low arterial pressure was associated with low arterial saturation and high arterial pressure with a saturation that was nearly normal.

The patient was an 18 year old Negro school girl. Her early history included spells of turning blue and fainting. She had recently suffered from a respiratory complaint which was incompletely diagnosed. Her convalescence was complicated by episodes of circulatory anoxia. These and the clinical cardiac findings led to an impression of possible congenital heart disease and she was referred to the University Hospital. Further study resulted in the impression of possible tetralogy of Fallot, and cardiac catheterization was advised.

On the first study (Oct. 28, 1948) blood samples from the right auricle, the right ventricle and the femoral artery were analyzed for oxygen and the saturation determined. The samples looked equally black and the patient was seen to have 
become very cyanotic. She also became restless and irrational but did not lose consciousness. The oxygen saturation of the right auricular and right ventricular and arterial blood was the same, $19 \%$, with no significant difference in the volume per cent figures.

These data seemed strange. They could be explained either on the theory 1) that the sample labeled "femoral arterial" came from the femoral vein, 2) that the pulmonary stream entered the systemic circuit via the bronchial veins and azygous trunk, or 3 ) that there had been a temporary cessation of pulmonary circulation and oxygen uptake.

The first of these had been nearly ruled out of our minds by the fact that the stream of black blood which issued from the puncture needle (Cournand type) pulsated and was under a high pressure. Nevertheless, a second arterial puncture was attempted. The procedure was difficult and painful and shortly the patient became very cyanotic again. The pressure tracing $(85 / 40 \mathrm{~mm}$. $\mathrm{Hg}$ ) is seen in Figure 1. The blood was very black and pulsated from the needle. Its oxygen saturation was only $15 \%$.

If any significant amount of arterialized blood drains into the superior vena cava from the bron- chial veins a sample taken in the region of the opening of the azygous should be higher in oxygen than one from the right auricle. At the time of a second catheterization a sample was taken from the superior vena cava to compare with one taken from the right auricle. The difference in per cent oxygen saturation (11, S.V.C.-10, R.A.) is not significantly beyond experimental error.

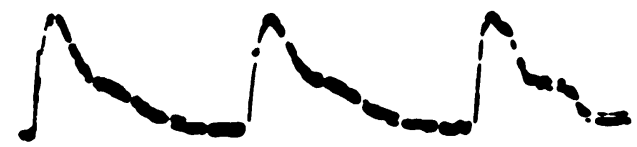

Fig. 1. Femoral Arterial Pressure Pulse $85 / 40 \mathrm{~mm}$. $\mathrm{Hg}$

Oxygen consumption was recorded during the second catheterization (Nov. 4, 1948). The apparatus was a Sanborn spring-balanced bell recorder which indicates, by a curved slope the presence of leaks. (The shape of the nose and lips, in the Negro, make it advisable to shut the nose and hold the mouth manually rather than to trust a nose clip and the subject's orbicularis oris.) As indicated in Figure 2, oxygen consumption was recorded properly with no leaks for some time. Then oxygen uptake ceased and after two minutes

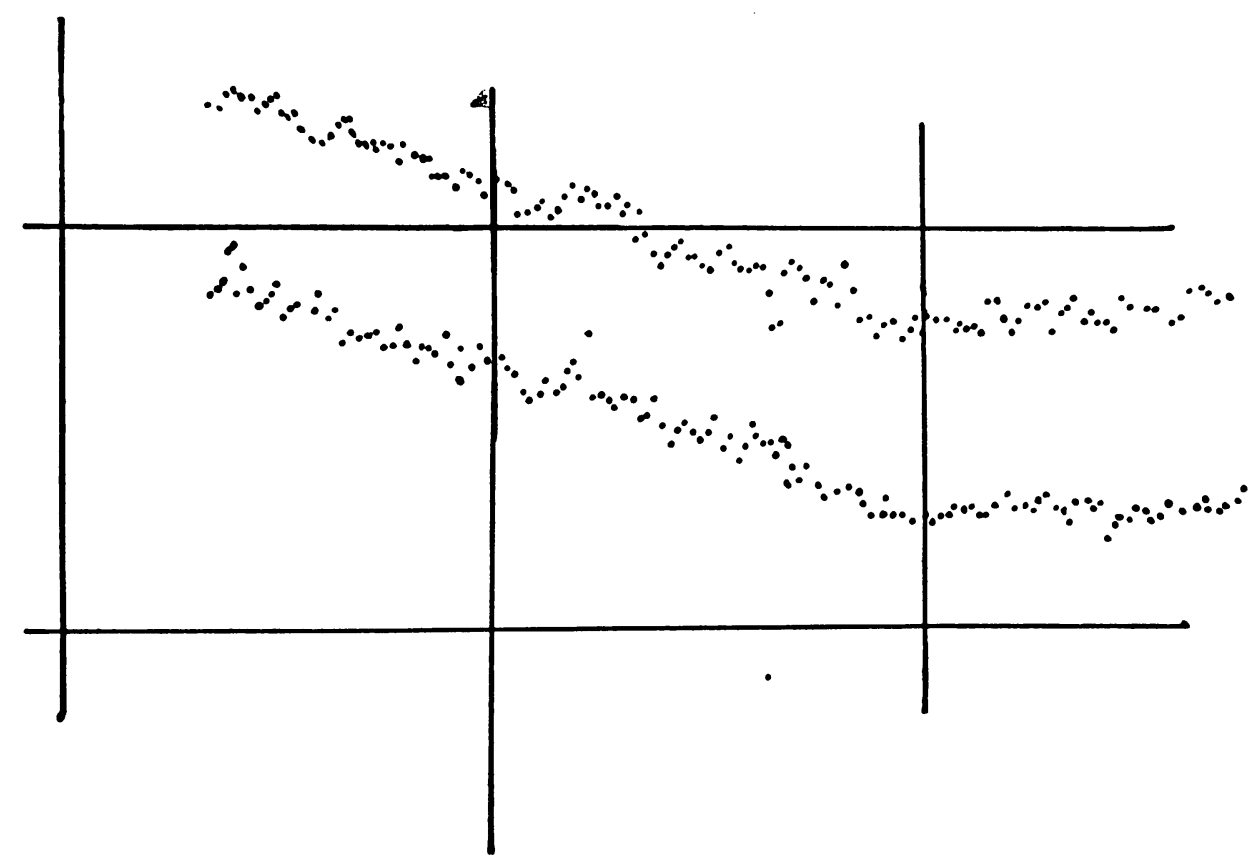

Fig. 2. Oxygen Consumption Curve During Cyanotic Episode (Tracing) Inspiration and expiration are marked by dots. 


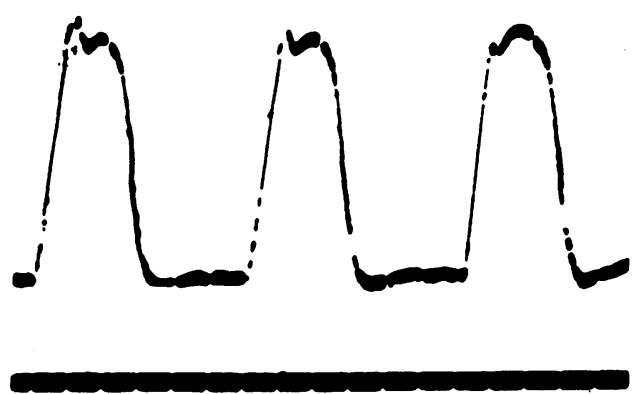

Fig. 3. Right Ventricular Pressure Pulse $100 / 0 \mathrm{~mm} . \mathrm{Hg}$

the patient became restless and pushed the mouthpiece away.

The various positions of the catheter are indicated in Figure 8. The pressures and oxygen saturations to correspond are shown in Table I. The fact that the catheter could be introduced through the aorta and up into the carotid artery indicates that the interventricular septum was patent. Pressures as recorded in the superior vena cava and right auricle were within normal limits. In the right ventricle systolic pressure was high and diastolic pressure low (Figure 3 ). The very low pressure and narrow pulse pressure in the pulmonary artery indicate a strong stenosis at the pulmonary valves (Figure 4). In the aorta (Figure 5) and femoral artery it was lower

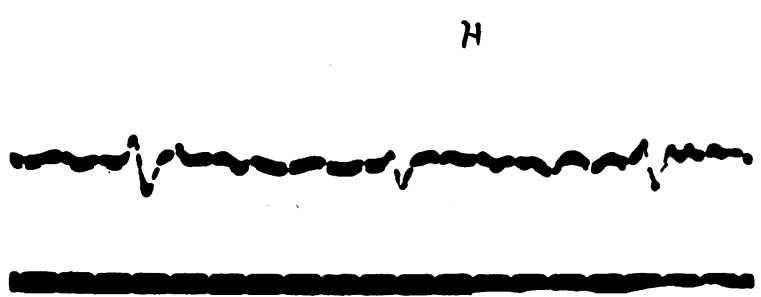

Fig. 4. Pressures in the Pulmonary Artery $5 / 0 \mathrm{~mm} . \mathrm{Hg}$

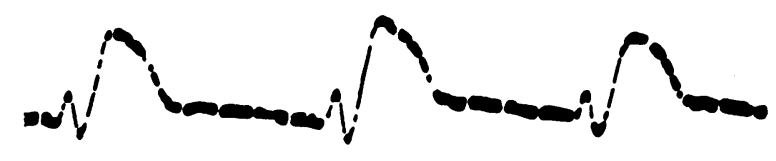

Fig. 5. Aortic Pressure Pulse $65 / 30 \mathrm{~mm}$. $\mathrm{Hg}$

than normal. The discrepancy between systolic pressure in the aorta and in the ventricle might indicate that there is also an aortic stenosis. The pressures were taken at different times and too much weight should not be attached to this difference since the systemic pressure levels were variable. The pattern of pressure in the heart and great vessels indicates that there is a pulmonary stenosis, and a widely patent interventricular sep-

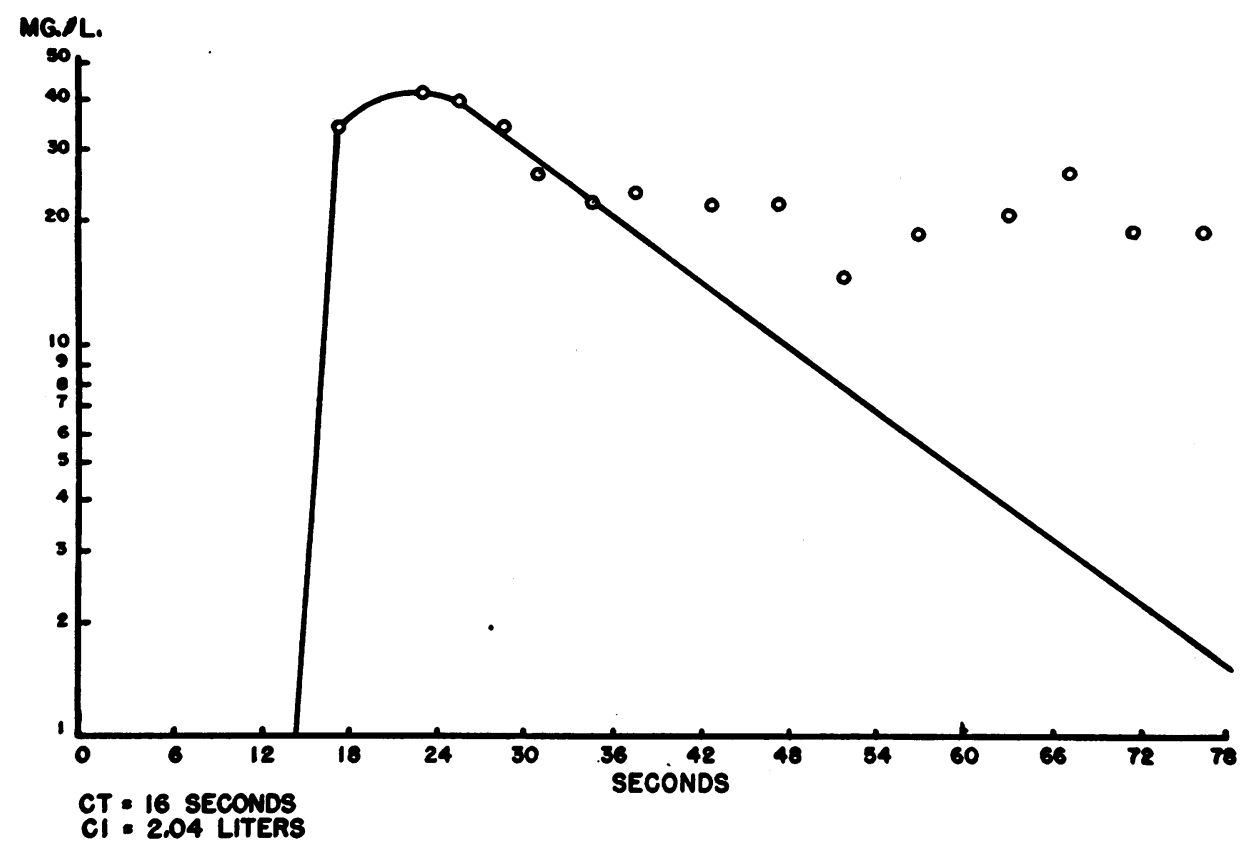

Fig. 6. Cardiac Output Curve by Dye Injection Method (Cardiac Index is $2.04 \mathrm{~L}$ ) 


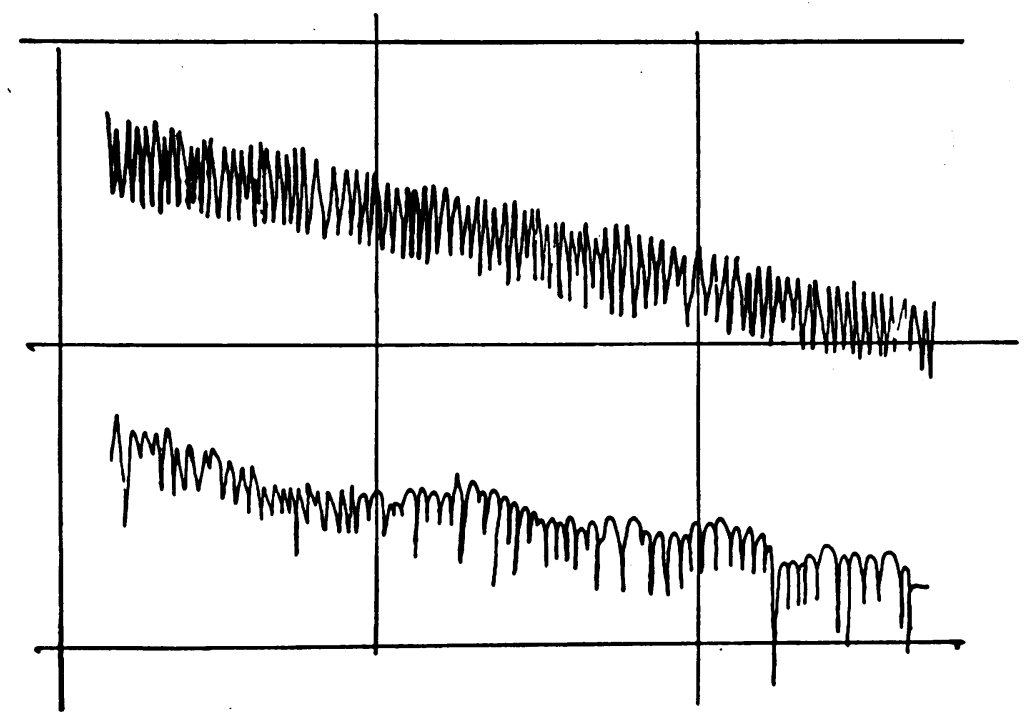

Fig. 7. Oxygen Consumption When Patient was not Cyanotic (Upper) and When She Was Slightly Cyanotic (Lower) After the Administration of T.E.A. (Tracing)

tum (functionally common ventricle) and is compatible with the diagnosis of tetralogy of Fallot.

A few days later the patient was no longer cyanotic, nor was she frequently subject to spells of circulatory anoxia. Her arterial pressure had gone up $(165 / 110)$ and the arterial saturation was $85 \%$.

Since no good veins were easily available for catheterization the circulatory dynamics were studied by the injection method (11) with the result seen in Figure 6. The arm to artery circulation time was $16 \mathrm{sec}$., a figure that is in the upper normal range. This indicates that there was no shunt at this time, carrying blood from the right side of the heart to the left. The slow curve of rise and fall of dye concentration indicates the possibility that there is a left to right shunt because such curves are usually associated with congestive failure of the circulation and an increased intrathoracic blood volume. A curve of this type can also be made by recirculation of pulmonary blood through intracardiac shunts (or a patent ductus) since this blood is dyed and gradually feeds out into the systemic circulation.

The calculation of the systemic blood flow (cardiac index) is not very secure because blood begins to recirculate before the descending straight line of the dye concentration curve is well established. The cardiac index by this calculation, however, was $2.04 \mathrm{~L}$ and is compatible with her apparent physiological condition.

At the beginning of this experiment the patient was not cyanotic, her arterial blood was a good red with a saturation of $85 \%$. Her arterial pres-

TABLE I

Results of catheterization

$\left(\mathrm{O}_{2}\right.$ Capacity 20 Vol. per cent)

\begin{tabular}{|c|c|c|c|c|c|c|c|c|c|c|c|}
\hline \multirow{2}{*}{ Date } & \multicolumn{5}{|c|}{$\mathrm{O}_{2}$ Saturation, per cent } & \multicolumn{6}{|c|}{ Pressure, $m m . H g$} \\
\hline & s.v.c. & $\stackrel{2}{\text { R.A. }}$ & $\stackrel{3}{\mathrm{v}}$. & P.A. & F.A. & s.v.c. & R.A. & $\stackrel{3}{\text { v. }}$ & $\begin{array}{l}4 \\
\text { P. }\end{array}$ & A. 5 & F.A. \\
\hline Oct. 28,1948 & - & 19 & 19 & - & 19 & 一 & 5 & $\frac{90}{00}$ & $\frac{7}{3}$ & - & - \\
\hline Oct. 31, 1948 & - & - & - & - & 15 & 一 & - & - & - & - & 85 \\
\hline Nov. 4, 1948 & 13 & 10 & 10 & 16 & 16 & 5 & 5 & $\frac{100}{0}$ & $\frac{5}{0}$ & $\frac{65}{30}$ & \\
\hline
\end{tabular}

\footnotetext{
* The numbers indicated in this row refer to positions of the catheter illustrated in Figure 8.
} 
TABLE II

Relation of oxygen saturation to arterial pressure

\begin{tabular}{|c|c|c|}
\hline$\cdot$ & $\begin{array}{c}\text { Arterial blood } \\
\text { per cent saturation }\end{array}$ & Blood pressure, $m m . H g$ \\
\hline $\begin{array}{l}\text { Cyanotic } \\
\text { Not cyanotic } \\
\text { Slight cyanosis }\end{array}$ & $\begin{array}{l}19-15 \\
85-72\end{array}$ & $\begin{array}{c}65 / 30 \\
165 / 110\end{array}$ \\
\hline $\begin{array}{l}\text { Anxiety } \\
\text { T.E.A. }\end{array}$ & $\begin{array}{l}68 \\
64\end{array}$ & $\begin{array}{l}110 / 60 \\
120 / 90\end{array}$ \\
\hline
\end{tabular}

sure was $165 / 110$. After the dye injection experiment she became uneasy. Her color was slightly cyanotic. The arterial pressure was $110 / 60$ and the arterial oxygen saturation was $63 \%$.

On another occasion the patient was not cyanotic, had an arterial pressure of $165 / 110$ and oxygen saturation of $72 \%$. The administration of tetra ethyl ammonium reduced the arterial pressure to $120 / 90$, the patient became slightly cyanotic and her arterial saturation was $64 \%$. Before administration of etamon the oxygen consumption was steady at a rate of $150 \mathrm{cc} . / \mathrm{min}$. (Figure 7, upper curve). After the blood pressure had been reduced the slope of the oxygen consumption curve became variable and the respirations irregular. The variability of the respirations accounts in some measure for the changes in the slope of the oxygen consumption curve. It seems however that the actual slope of the curve varies from one somewhat steeper than the control to one that is considerably less steep (Figure 7 , lower curve) indicating an actual variation in the oxygen uptake.

\section{DISCUSSION}

The data are summarized in Tables I and II and in Figure 8. During both catheterization experiments no clear arteriovenous oxygen difference could be established. The oxygen consumption measurements indicate that the patient during the placement of the catheter was consuming oxygen at the rate of $190 \mathrm{cc}$. $/ \mathrm{min}$. and that before the samples were taken the oxygen uptake in the lungs fell off to zero. Similarly the oxygen uptake became smaller than normal as she entered a period of hypotension and cyanosis under the influence of T.E.A. Hypotension resulting from anxiety was also associated with a low oxygen saturation.

When she was not cyanotic her blood pressure was high and the dye injection experiment indicated that either there was no right to left shunt or that it was minimal. Since release from the hospital she has maintained good health, been free of noticeable cyanosis and showed blood pressures of $180 / 140$ to $220 / 150$.

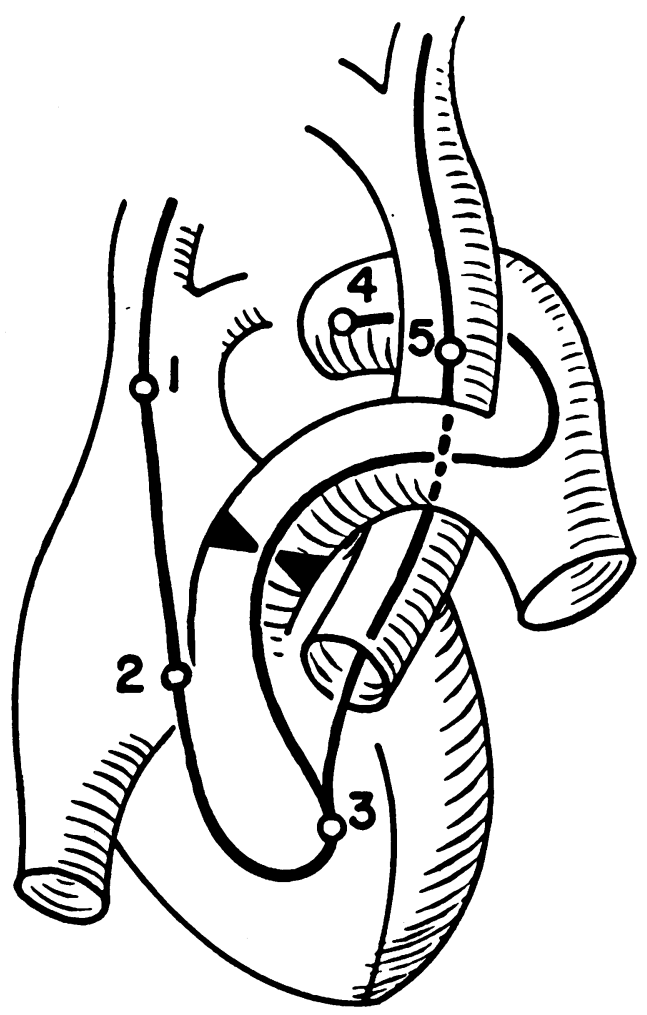

Fig. 8. Diagram of the Heart in the Case Under Discussion with Indications of the Place of Taking the Samples and Pressures Mentioned in Table I

The very large variation in arterial oxygen saturation (from $15 \%$ to $85 \%$ ) and the results of the dye injection experiment necessitates, in view of the introductory consideration, the conclusion that the right to left intracardiac shunt must vary from nearly zero to about $100 \%$. The pressure relations between pulmonary artery and ventricle indicate that the pulmonary resistance is established by a strong stenosis which cannot be affected by vasomotor influences. The mechanism by which blood is diverted into and away from the pulmonary circuit therefore must reside elsewhere than in the pulmonary circuit itself.

The simplest hypothesis which will cover the above data is that the functionally common ventricle pushes blood out either the pulmonary artery or the systemic aorta as governed by the relative resistance in each bed. As the systemic re- 
sistance falls, as indicated by a low arterial pressure, more and more blood passes out the systemic stream, less and less out the pulmonary stream, the right to left shunt becomes greater and greater, and the oxygen saturation becomes less and less. In the period from Oct. 28 to Nov. 4 it would seem that there were times when no blood flowed through the lungs and the intracardiac shunt was $100 \%$.

The deciding factor which determines whether the blood is, or is not to go out past the pulmonary stenosis is the ventricular pressure. In this case the stenosis is severe and a pressure of $100 \mathrm{~mm}$. $\mathrm{Hg}$ hardly suffices to force open the pulmonary artery. Unless the ventricular pressure is higher than this during systole the blood entering by way of the venae cavae is all shunted across into the aorta. This is shown by the fact that the mixed venous and arterial oxygen saturations were the same.

In this patient the lowering of pressure in the ventricle seems to have been in response to peripheral systemic dilation. The heart beat was strong and the rate was rapid. The pulse pressure was $35 \mathrm{~mm}$. $\mathrm{Hg}$ in the aorta indicating a stroke index of about $35 \mathrm{cc}$. according to the calculations of Remington et al. (12). The circulation index is therefore approximately $3.5 \mathrm{~L}$, a higher figure than was given by the dye injection method when the patient was not cyanotic.

To say that cardiac weakness or inhibition was not responsible for the cyanosis in this case is not to say that it could not be responsible in other cases. A patient with a widely patent interventricular septum, during syncope due to vagal cardiac inhibition, would in addition to the systemic and cerebral ischemia, be suffering from arterial anoxemia with cyanosis because the same condition which lowers the systemic arterial pressure would also lower the amount of blood passing the pulmonary resistance and coming into a position to take up oxygen. As a rule, however, both cardiac and vascular elements play a role in producing circulatory collapse. Anxiety, excitement, pain and other stresses seem to reduce the peripheral resistance (13-17), particularly that in the blood vessels to the skeletal muscles (18-20). This serves to increase blood flow through these organs and leads to their efficient working. Whether it also leads to a lowering of blood pres- sure depends upon whether cardiac action can be augmented in sufficient measure to maintain blood pressure. Factors which may interfere with such augmentation of cardiac action are vagus stimulation, resulting in asystole, bradycardia, or weakened contraction, postural failure of venous return, failure of venous return due to natural pooling of blood in the periphery resulting from vasodilatation, or pooling from the experimental use of tourniquets. Also the heart may be handicapped by structural defects, as is the case in our patient, and the structural defects lead to arterial anoxemia, a circumstance that is not evident in the normal circulation even during syncope.

It is interesting to note that many children with cyanotic heart disease learn to react to episodes of dyspnea and weakness by squatting. This posture certainly improves venous return and by pressure on the great abdominal and leg arteries may increase slightly the systemic resistance. The maneuver may be expected therefore to increase the systolic ventricular pressure in sufficient measure to augment the stream which must pass the pulmonary resistance and thus to increase oxygen uptake. It would also seem rational to expect supportive action from vasoconstrictor drugs (arterenol, phenylephrine [neosynephrine], etc. but not epinephrine $[13,17])$.

The fact that the pulmonary arterial saturation became as low as $16 \%$ indicates, on reference to the standard oxygen dissociation curve, that the cells of the body are able to extract oxygen from the blood until its tension is about $12 \mathrm{~mm}$. $\mathrm{Hg}$. Samples from the right auricle and ventricle showed lower saturations still but mixing of venous streams may not have yet been complete. Different organs are able to extract varying amounts of oxygen from blood. The heart, and probably active skeletal muscle take out a large part of the oxygen displayed before them in the blood (21). The kidney takes comparatively little and the proportion it takes is not increased as the oxygen supply decreases (22). The brain is intermediate in this regard (23). In this patient the mixed blood returning from the body as a whole was reduced in oxygen content to a figure comparable to that seen in normal coronary blood. She became somewhat distracted but did not lose consciousness. 
It is interesting to speculate on the physiological role of the high resistance to pulmonary blood flow which is seen in the presence of an open ventricular septum. If the septum is widely enough open so that the ventricle is functionally a single chamber the normal pulmonary resistance is such that all of the ventricular output would pass through the lungs at pressures far below those which are necessary in the systemic arteries to support life. The normal pulmonary pressure goes up very little in exercise (24) and under the influence of drugs which increase greatly the blood flow (7). The minimal increases in pulmonary arterial pressure, which do occur as the blood flow goes up, distend the pulmonary bed so that the resistance to flow decreases as the flow increases. This would mean that even if the common ventricle put out twice as much blood as either a normal right or a normal left ventricle the mean pressure in both aorta and pulmonary artery would never exceed $20-25 \mathrm{~mm}$. $\mathrm{Hg}$ so long as pulmonary resistance were normal.

The pulmonary stenosis which is the consequence of abnormal embryonic development in the tetralogy of Fallot raises the pulmonary resistance so that blood is sent out the systemic arteries at an adequate pressure.

In the Eisenmenger complex and probably in cor triloculare biatrium and cor biloculare, a high resistance to pulmonary blood flow exists in the lungs (3). It seems to be due to arteriolar changes. This resistance is necessary to raise the pressure in the systemic arteries to physiological levels and to prevent the ventricle discharging all its blood out the pulmonary artery. These arteriolar changes may overcompensate and produce a right to left shunt, though the usual patient shows a moderate shunt from left to right. The stimulus which may produce these arteriolar changes is hard to imagine. In the normal fetus the resistance of the collapsed lungs is high, and most of the left ventricular output is carried by the ductus arteriosus. Pressures in the two ventricles are identical and the presence of a patent ventricular septum would have no consequences. It is only as the first breath is taken that the pulmonary resistance falls and a pressure difference is established between the right and left ventricles (25).

It seems obvious that if this normal sequence of events should occur in the presence of a widely open ventricular septum, there would, as soon as breathing began, be a left to right shunt of nearly $100 \%$ and severe systemic hypotension. This disaster is prevented by the pulmonary arteriolar changes mentioned above. Since there seems to be no possible abnormality of hemodynamics in fetal life which could account for the development of the arteriolar resistance it would seem that they must be the result of post-natal changes. A study of blood pressure in infants with Eisenmenger syndrome or with cor triloculare biatrium would be very instructive.

\section{SUMMARY}

A patient, subject to episodes of cyanosis as a result of congenital heart disease, presents data by the methods of cardiac catheterization and dye injection which indicate that the intracardiac shunt varies from zero to $100 \%$ as the arterial pressure falls from $165 / 110$ to $65 / 30$. Uptake of oxygen in the lungs ceased for periods lasting up to two minutes and the saturation of the mixed venous blood and of the arterial blood came to the same very low figure. This indicates that uptake by the cells continued down to a saturation of $15-19 \%$ or 11-14 mm. $\mathrm{Hg} \mathrm{O}$ tension.

\section{BIBLIOGRAPHY}

1. Abbott, M. E., Atlas of Congenital Cardiac Disease. The Am. Heart Assn., New York, 1936.

2. Bing, R. J., Vandam, L. D., and Gray, F. D., Jr., Physiological studies in congenital heart disease. II. Results of preoperative studies in patients with tetralogy of Fallot. Bull. Johns Hopkins Hosp., 1947, 80, 121.

3. Bing, R. J., Vandam, L. D., and Gray, F. D., Jr., Physiological studies in congenital heart disease. III. Results obtained in five cases of Eisenmenger's Complex. Bull. Johns Hopkins Hosp., 1947, 80, 323.

4. Handelsman, J. C., Bing, R. J., Campbell, J. A., and Griswold, H. E., Physiological studies in congenital heart disease. V. The circulation in patients with isolated septal defects. Bull. Johns Hopkins Hosp., 1948, 82, 615.

5. Taussig, H. B., Congenital Malformations of the Heart. Commonwealth Fund, New York, 1947.

6. Dexter, L., Haynes, F. W., Burwell, C. S., Eppinger, E. C., Seibel, R. E., and Evans, J. M., Studies of congenital heart disease. I. Technique of venous catheterization as a diagnostic procedure. J. Clin. Invest., 1947, 26, 547. 
7. Dexter, L., Haynes, F. W., Burwell, C. S., Eppinger, E. C., Sagerson, R. P., and Evans, J. M., Studies of congenital heart disease. II. The pressure and oxygen content of blood in the right auricle, right ventricle and pulmonary artery in control patients, with observations on the oxygen saturation and source of pulmonary "capillary" blood. J. Clin. Invest., 1947, 26, 554.

8. Dexter, L., Haynes, F. W., Burwell, C. S., Eppinger, E. C., Sosman, M. C., and Evans, J. M., Studies in congenital heart disease. III. Venous catheterization as a diagnostic aid in patent ductus arteriosus, tetralogy of Fallot, ventricular septal defect and auricular septal defect. J. Clin. Invest., 1947, 26, 561.

9. Hamilton, W. F., Woodbury, R. A., and Vogt, E., Differential pressures in the lesser circulation of the unanesthetized dog. Am. J. Physiol., 1939, 125, 130.

10. Motley, H. L., Cournand, A., Werko, L., Himmelstein, A., and Dresdale, D., The influence of short periods of induced acute anoxia upon pulmonary artery pressures in man. Am. J. Physiol., 1949, 150, 315.

11. Hamilton, W. F., Riley, R. L., Attyah, A. M., Cournand, A., Fowell, D. M., Himmelstein, A., Noble, R. P., Remington, J. W., Richards, D. W., Jr., Wheeler, N. C., and Witham, A. C., Comparison of Fick and dye injection methods of measuring cardiac output in man. Am. J. Physiol., 1948, 153, 309.

12. Remington, J. W., Noback, C. R., Hamilton, W. F., and Gold, J. J., Volume elasticity characteristics of the human aorta and prediction of the stroke volume from the pressure pulse. Am. J. Physiol., 1948, 153, 298.

13. McMichael, J., and Sharpey- Schafer, E. P., Cardiac output in man by a direct Fick method. Brit. Heart J., 1944, 6, 33.

14. Stead, E. A., Jr., Warren, J. V., Merrill, A. F., and Brannon, E. S., The cardiac output in male subjects as measured by the technic of right atrial catheterization. Normal values with observations on the effect of anxiety and tilting. J. Clin. Invest., 1945, 24, 326.

15. Warren, J. V., Brannon, E. S., Stead, E. A., Jr., and Merrill, A. J., The effect of venesection and the pooling of blood in the extremities on the atrial pressure and cardiac output in normal subjects with observations on acute circulatory collapse in three instances. J. Clin. Invest., 1945, 24, 337.

16. Hickam, J. B., Cargill, W. H., and Golden, A., Cardiovascular reactions to emotional stimuli. Effect on the cardiac output, arteriovenous oxygen difference, arterial pressure and peripheral resistance. J. Clin. Invest., 1948, 27, 290.

17. Goldenberg, M., Pines, K. L., Baldwin, E. de F., Greene, D. G., and Roh, C. E., Hemodynamic response of man to nor-epinephrine and epinephrine and its relation to the problem of hypertension. Am. J. Med., 1948, 5, 792.

18. Barcroft, H., Edholm, O. G., McMichael, J., and Sharpey-Schafer, E. P., Post haemorrhagic fainting. Study by cardiac output and forearm flow. Lancet, 1944, 1, 489.

19. Barcroft, H., and Edholm, O. G., On the vasodilation in human skeletal muscle during post-haemorrhagic fainting. J. Physiol., 1945, 104, 161.

20. Anderson, D. P., Barcroft, H., Allen, W. J., Edholm, O. G., and Manning, G. W., Circulatory changes during fainting and coma caused by oxygen lack. J. Physiol., 1946, 104, 426.

21. Eckenhoff, J. E., Hafkenschiel, J. H., Foltz, E. L., and Driver, R. L., Influence of hypotension on coronary blood flow, cardiac work and cardiac efficiency. Am. J. Physiol., 1948, 152, 545.

22. Dole, V. P., Emerson, K., Jr., Phillips, R. A., Hamilton, P., and Van Slyke, D. D., The renal extraction of oxygen in experimental shock. Am. J. Physiol., 1946, 145, 337.

23. Kety, S. S., and Schmidt, C. F., The effects of altered arterial tensions of carbon dioxide and oxygen on cerebral blood flow and cerebral oxygen consumption of normal young men. J. Clin. Invest., 1948, $27,484$.

24. Riley, R. L., Himmelstein, A., Motley, H. L., Weiner, H. M., and Cournand, A., Studies of pulmonary circulation at rest and during exercise in normal individuals and in patients with chronic pulmonary disease. Am. J. Physiol., 1949, 152, 372.

25. Hamilton, W. F., Woodbury, R. A., and Woods, E. B., The relation between systemic and pulmonary blood pressures in the fetus. Am. J. Physiol., 1937, 119, 206. 